\title{
Suspected Smith-Lemli-Opitz-Syndrome: A Very Rare Syndrome
}

Deepak Sharma*, Aakash Pandita, Srinivas Murki, Tejo Pratap and Vasikarla Madhavi

Department of Neonatology, Fernandez Hospital, Hyderabad, India

*Corresponding author: Deepak Sharma, Department of Neonatology, Fernandez Hospital, Hyderabad, India, Tel: +919462270002; E-mail: dr.deepak.rohtak@gmail.com

Rec date: 04 Oct 2014; Acc date: 15 Oct 2014; Pub date: 17 Oct 2014

Copyright: $\odot 2014$ Sharma D, et al. This is an open-access article distributed under the terms of the Creative Commons Attribution License, which permits unrestricted use, distribution, and reproduction in any medium, provided the original author and source are credited.

\begin{abstract}
Smith-Lemli-Opitz syndrome (SLOS) is an inborn error of metabolism for cholesterol synthesis. The enzyme defect involved in the syndrome is mutation of 7-Dehydrocholesterol reductase (DHCR7) which leads to increase in plasma concentration of 7- and 8-dehydrocholesterol (DHC) levels. The affected patients have different presentation and usually involve all systems of the body. We report a newborn who was diagnosed as case of SLOS on the basis of clinical and biochemical investigation.
\end{abstract}

Keywords: Smith-Lemli-Opitz-Syndrome; 7-Dehydrocholesterol Reductase; 7- and 8-Dehydrocholesterol; Cholesterol

\section{Introduction}

The Smith-Lemli-Opitz syndrome (SLOS [MIM 270400]) is a rare autosomal recessive syndrome that indicates a great variability with respect to the harshness of its introduction. SLOS is caused by variations in the $\Delta 7$ sterol-reductase gene (DHCR7), which disrupt cholesterol biosynthesis. SLOS is characterized by both antenatal and postnatal growth retardation, microcephaly, decreased intelligence and various deformities. Major malformations include distinctive facial features, cleft palate, postaxial polydactyly, 2-3 syndactyly of the toes, and underdeveloped external genitalia in males, while internal anomalies may affect every organ system. SLOS is confirmed by laboratory test showing elevated concentration of 7DHC, cholesterol precursor in serum or other tissues and by the presence of two DHCR7 mutations. The enzymatic deficiency results in low cholesterol with elevated 7DHC levels, both during intrauterine and postnatally [1]. We describe a newborn who was diagnosed as a case of SLOS on the basis of clinical and biochemical investigation.

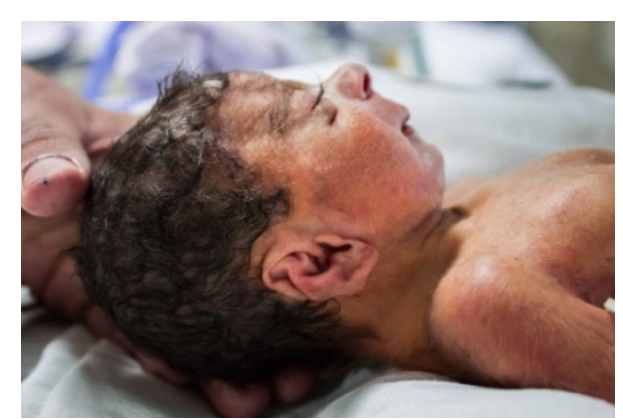

Figure 1: Low set ears with retrognathia (Note: The infant is having hypertrichosis)

\section{Case Discussion}

A preterm infant was delivered at 30 weeks of gestation to Gravida 4 Para3 Abortion 0 Live 3 mother by emergency cesarean section because of Doppler compromise (Reversal of end diastolic blood flow). The baby was diagnosed antenatally to have fetal growth restriction (2nd percentile) with Doppler abnormality. The infant received a full course of antenatal steroid for better neonatal outcome. The baby didn't cry after birth and required resuscitation in the form of bag and mask ventilation for 30 second with an Apgar score of 4/6/6 at one, five and ten minutes respectively. The baby had respiratory distress at birth and $\mathrm{x}$-ray was suggestive of Hyaline membrane disease for which surfactant was given by INSURE method. The infant was diagnosed to have low set ears (Figure 1), maxillary hypoplasia (Figure 2), maxillary alveolar ridge hypertrophy (Figure 3), retrognathia, long eyelashes, hypertrichosis, and smooth philtrum. The limbs had syndactyly of second and third toes with short and stubby fingers (Figure 4) and simian crease. Genital examination showed pen scrotal hypospadias with undescended testis (Figure 5). Systemic examination showed pan systolicmurmur. The infant was symmetrical IUGR with weight 1170 gram $(<10$ centile), length $35 \mathrm{~cm} \quad(<10$ centile), and head circumference $25.5 \mathrm{~cm}$ ( $<10$ centile). The infant had jitteriness which on investigation showed hypoglycemia which was managed with fluid. The infant was evaluated with ECHO that showed DORV (Double outlet right ventricle) with large sub aortic VSD, side by side great vessels, small PDA and with high PVR.There was no associated abnormality of the descending and abdominal aorta.The head ultrasound showed bilateral grade $2 \mathrm{IVH}$ with bilateral frontal cyst. The renal scan showed bilateral kidney of normal size with prominent pelvicalyceal junction. The whole body $\mathrm{x}$-ray was normal. The laboratory investigation showed normal serum electrolytes, calcium and coagulation profile. Suspecting Smith Lemli-Opitz syndrome we planned serum cholesterol level which showed low value of $43 \mathrm{mg} / \mathrm{dl}$ (normal value $=150-250 \mathrm{mg} / \mathrm{DL})$. The parents were counselled for gene analysis but due to financial constraints they didn't agreed for gene analysis. Hence on the foundation of clinical characteristics and science lab test we kept diagnosis of Smith- Lemli-Opitz syndrome. The infant succumbed to death as parents were not willing for any management of the infant in view of poor final result. 


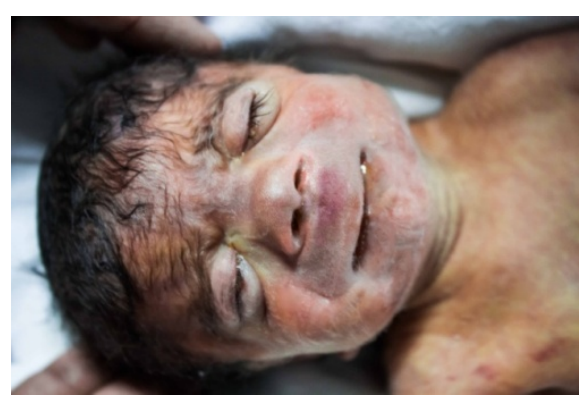

Figure 2: Maxillary hypoplasia in the infant

\section{Discussion}

Smith-Lemli-Opitz syndrome (SLOS) is an autosomal recessive inherited syndrome, which has varied manifestation resulting from deficiency of the enzyme which is taken for a final synthesis of cholesterol [2]. This enzyme defect causes low plasma cholesterol levels and increased 7- and 8-dehydrocholesterol (DHC) levels [3]. The unique lipid profile in SLOS is the consequence of deficient activity of 3 beta-hydroxysterol-delta 7-reductase (7dehydrocholesterol-delta 7-reductase [DHCR7] EC 1.3.1.21) [4]. The DHCR7 gene is localized to chromosome 11q11-13.

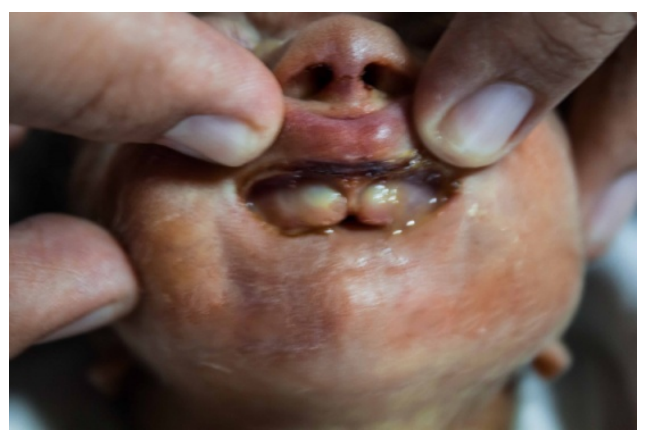

Figure 3: Maxillary alveolar ridge hypertrophy in infant

The incidence of Smith-Lemli-Opitz syndrome has been estimated to be around 1 in 20000 [5]. There are very few case report from our country [6,7]. The clinical features are varied which include multiple congenital malformations, behavioral disability and low intelligence levels. The common features of syndrome includes microcephaly, short nasal root, bitemporal narrowing, cleft palate or bifid uvula, low set ears, ptosis of eyelids, microganthia, simian crease, syndactyly of the second and third toe fingers, rhizomelia, growth retardation, failure to thrive, polydactyly of the hands. Genitourinary system malformations include various abnormalities including hypospadias, cryptorchidism, micropenis, ambiguous genitalia, bifid scrotum, upper tract anomalies, ureteropelvic junction obstruction, hydronephrosis, renal malformations including renal cystic dysplasia, renal duplication, renal agenesis. Cardiovascular malformation includes endocardial cushion defect, hypoplastic left heart syndrome, ASD, patent ductus arteriosus, double outlet right ventricle, membranous ventricular septal defect and hypertension $[1,8]$. These neonates are prone to have descending aorta abnormalities too as the lipid profile characteristics also effects the abdominal aorta [9]. The functional assessment of these newborns to be performed by using Tissue Doppler Imaging (TDI), which provide further significant information about these neonatal cardiac functions [10]. Nervous system malformation includes agencies of corpus callosum, generalized hypotonia and microcephaly. Other rare associated malformations include diaphragmatic hernia, anal atresia, thymus hypoplasia, sacral dimple, pyloric stenosis, Hirschsprung's disease. Demirdöven et al described a typical case of SLOS with annular pancreas, which was an unreported gastrointestinal abnormality [11].

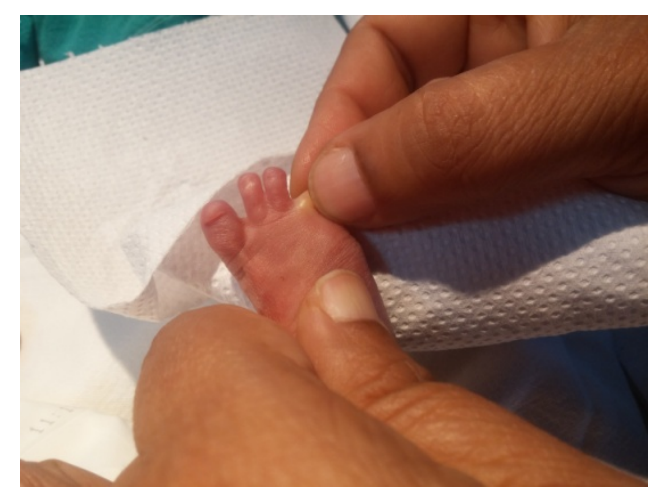

Figure 4: Lower limbs having syndactyly of second and third toes with short and stubby fingers

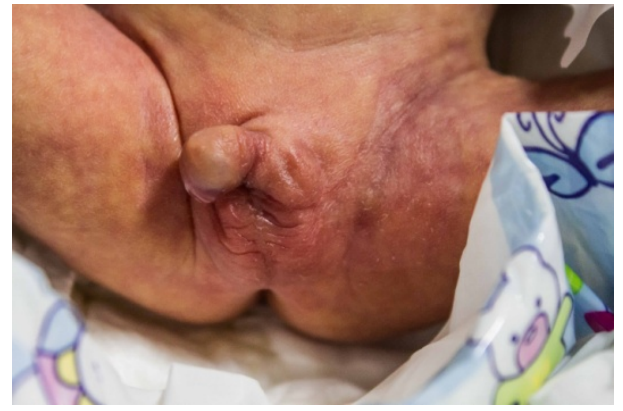

Figure 5: Genital with penoscrotal hypospadias with undescended testis

The behavioral problems include self-mutilations, ADHD, autism, irritability, aggressive behavior [1]. The fetus can be suspected of having SLOS syndrome by finding malformations, growth retardation and decreased fetal movements [12]. Quelin et al. in there interesting study on phenotypic spectrum of fetal Smith-Lemli-Opitz syndrome reported rare fetal malformation which was unreported in literature like ulnar hypoplasia, vertebral segmentation anomalies, congenital pulmonary adenomatoid malformation, fused lungs, gastroschisis, holomyelia and hypothalamic hamartoma [13]. These individuals are usually growth restricted postnatally too.A study conducted by Lee et al showed that the majority of the affected individuals were less than 2 standard deviation on CDC chart and hence they plotted new growth chart for SLOS patients [14]. These patients are have intrauterine growth retardation with prematurity which contribute towards an increased cardiovascular risk in preterm neonates hence an early, constant, and prolonged cardiological follow-up programmed needs to 
be implemented in these individuals [15]. The patients usually have low cholesterol and low LDL values. The diagnosis is confirmed by demonstrating elevated 7DHC in plasma or tissues by Tandem Mass spectrometry. DHCR7 mutation analysis is done to confirm a diagnosis of SLOS or in few cases where biochemical testing is inconclusive [16]. Antenatal diagnosis can be made as early as 16 weeks of gestation by documenting low level of amniotic fluid cholesterol and increased 7-dehydrocholesterol with undetectable amniotic fluid unconjugated estriol [17]. The spectrum of SLOS severity depends on DHCR7 genotype and maternal ApoE genotype, but a large part of the clinical variability remains unexplained $[18,19]$. Lanthaler et al. in there study showed that maternal ABCA1 genotype is associated with severity of SLOS and with viability of patients who homozygous for null mutations, raising the possibility that ABCA1 genotype may also plays a crucial role in the viability of SLOS fetuses, although presently the mode of action is not clear [20]. Over 130 different mutations of DHCR7 have been identified in SLOS patients. The most frequently reported mutation is a splice acceptor mutation, c.964-1G4C. Other 'common' alleles include p.T93M, p.W151X, p.R404C, and p.V326L [16]. Although not currently available as a clinical test, measurement of 7-dehydropregnanetriol/pregnanetriol,8dehydropregnanetriol/pregnanetriol, (7p8) dehydropregnanetriol/ pregnanetriol or dehyroestriol/estriol ratios in maternal urine appear to be a beam of light for prenatal test but more studies are required for confirming there sensitivity and specificity [21]. There is no definitive treatment option for SLOS. The treatment options include cholesterol supplementation in form of egg yolk or cholesterol suspension [22]. 3Hydroxy-3-methylglutaryl coenzyme A (HMG-CoA) reductase inhibitors (statins) have been tried as potential therapy for SLOS. The statins inhibit the enzymes prior to the enzyme defects in SLOS hence decreasing the 7DHC levels [23]. The prenatal genetic counselling of the parents is very important and they should be told about the risk of fetal involvement by SLOS. The prenatal diagnostic test can be either biochemical which includes sterol analysis using either amniotic fluid or a chorionic villus sample or by molecular testing [24]. Craig et al. reported 'SLOS screening algorithm' based on maternal serum uE3, human chorionic gonadotropin and a-fetoprotein protein levels can be used to identify fetuses with SLOS [25]. The main limitation of our case was that though the neonate had physical and biochemical features of SLOS, the genetic analysis would have confirmed our case.

\section{Conclusion}

The future direction of SLOS includes new diagnostic methods which are confirmatory, cheap, and rapid and have high sensitivity and specificity and that can be performed easily. The treatment options of SLOS are limited and future therapies are required which can stop the neurodevelopmental damage caused by absence of cholesterol to neurons. There is requirement of regular follow up of these affected individuals as they are prone to develop various cardiac and neurodevelopmental problems in follow up.

\section{References}

1. Nowaczyk MJ, Irons MB (2012) Smith-Lemli-Opitz syndrome: phenotype, natural history, and epidemiology.Am J Med Genet C Semin Med Genet 160C: 250-262.

2. Smith DW, Lemli L, Opitz JM (1964) A Newly Recognized Syndrome Of Multiple Congenital Anomalies. J Pediatr 64: 210-217.

3. Batta AK, Tint GS, Shefer S, Abuelo D, Salen G (1995) Identification of 8dehydrocholesterol (cholesta-5,8-dien-3 beta-ol) in patients with SmithLemli-Opitz syndrome.J Lipid Res 36: 705-713.
4. Shefer S, Salen G, Batta AK, Honda A, Tint GS, et al. (1995) Markedly inhibited 7-dehydrocholesterol-delta 7-reductase activity in liver microsomes from Smith-Lemli-Opitz homozygotes. J Clin Invest 96: 1779-1785.

5. Jones KL, Smith DW (2005) Smith's recognizable patterns of human malformation. 6 th ed. Philadelphia: Saunders.

6. Scott JX, Praburam PM (2004) Smith-Lemli-Opitz syndrome.Indian Pediatr 41: 512 .

7. Gedam R, Shah I, Ali U, Ohri A (2012) Smith-Lemli-Opitzsyndrome.Indian J Hum Genet 18: 235-237.

8. Al-Owain M, Imtiaz F, Shuaib T, Edrees A, Al-Amoudi M, et al. (2012) Smith-Lemli-Opitz syndrome among Arabs.Clin Genet 82: 165-172.

9. Ciccone MM, Scicchitano P, Salerno C, Gesualdo M, Fornarelli F, et al. (2013) Aorta structural alterations in term neonates: the role of birth and maternal characteristics.Biomed Res Int 2013: 459168.

10. Ciccone MM, Scicchitano P, Zito A, Gesualdo M, Sassara M, et al. (2011) Different functional cardiac characteristics observed in term/preterm neonates by echocardiography and tissue doppler imaging.Early Hum Dev 87: 555-558.

11. Demirdoven M, Yazgan H, Korkmaz M, Gebesce A, Tonbul A (2014) Smith-lemli-opitz syndrome: a case with annular pancreas.Case Rep Pediatr 2014: 623926.

12. Hagen MA, Stuurman KE, de Vries JI (2013) Abnormal motor behavior at 23 weeks in a fetus with Smith-Lemli-Opitz syndrome (SLOS).PrenatDiagn 33: 807-809.

13. Quélin C, Loget P, Verloes A, Bazin A, Bessières B, et al. (2012) Phenotypic spectrum of fetal Smith-Lemli-Opitz syndrome.Eur J Med Genet 55: 81-90.

14. Lee RW, McGready J, Conley SK, Yanjanin NM, Nowaczyk MJ, et al. (2012) Growth charts for individuals with Smith-Lemli-Opitz syndrome.Am J Med Genet A 158A: 2707-2713.

15. Mercuro G, Bassareo PP, Flore G, Fanos V, Dentamaro I, et al. (2013) Prematurity and low weight at birth as new conditions predisposing to an increased cardiovascular risk.Eur J PrevCardiol 20: 357-367.

16. Porter FD (2008) Smith-Lemli-Opitz syndrome: pathogenesis, diagnosis and management.Eur J Hum Genet 16: 535-541.

17. Irons M, Elias ER, Tint GS, Salen G, Frieden R, et al. (1994) Abnormal cholesterol metabolism in the Smith-Lemli-Opitz syndrome: report of clinical and biochemical findings in four patients and treatment in one patient.Am J Med Genet 50: 347-352.

18. Witsch-Baumgartner M, Fitzky BU, Ogorelkova M, Kraft HG, Moebius FF, et al. (2000) Mutational spectrum in the Delta7-sterol reductase gene and genotype-phenotype correlation in 84 patients with Smith-LemliOpitz syndrome.Am J Hum Genet 66: 402-412.

19. Witsch-Baumgartner M, Gruber M, Kraft HG, Rossi M, Clayton P, et al. (2004) Maternal apo E genotype is a modifier of the Smith-Lemli-Opitz syndrome.J Med Genet 41: 577-584.

20. Lanthaler B, Steichen-Gersdorf E, Kollerits B, Zschocke J, WitschBaumgartner M (2013) Maternal ABCA1 genotype is associated with severity of Smith-Lemli-Opitz syndrome and with viability of patients homozygous for null mutations.Eur J Hum Genet 21: 286-293.

21. Shackleton $\mathrm{CH}$, Marcos J, Palomaki GE, Craig WY, Kelley RI, et al. (2007) Dehydrosteroid measurements in maternal urine or serum for the prenatal diagnosis of Smith-Lemli-Opitz syndrome (SLOS).Am J Med Genet A 143A: 2129-2136.

22. Svoboda MD, Christie JM, Eroglu Y, Freeman KA, Steiner RD (2012) Treatment of Smith-Lemli-Opitz syndrome and other sterol disorders.Am J Med Genet C Semin Med Genet 160C: 285-294.

23. Jira PE, Wevers RA, de Jong J, Rubio-Gozalbo E, Janssen-Zijlstra FS, et al. (2000) Simvastatin. A new therapeutic approach for Smith-Lemli-Opitz syndrome.J Lipid Res 41: 1339-1346.

24. Kratz LE, Kelley RI (1999) Prenatal diagnosis of the RSH/Smith-LemliOpitz syndrome.Am J Med Genet 82: 376-381. 
Citation: Sharma D, Pandita A, Murki S, Pratap T, Madhavi V (2014) Suspected Smith-Lemli-Opitz-Syndrome: A Very Rare Syndrome. J Neonatal Biol 3: 161. doi:10.4172/2167-0897.1000161

Page 4 of 4

25. Craig WY, Haddow JE, Palomaki GE, Kelley RI, Kratz LE, et al. (2006)

Identifying Smith-Lemli-Opitz syndrome in conjunction with prenatal screening for Down syndrome.Prenat Diagn 26: 842-849. 